\title{
Erratum for Reitzel et al., "Minocycline-EDTA-Ethanol Antimicrobial Catheter Lock Solution Is Highly Effective In Vitro for Eradication of Candida auris Biofilms"
}

Ruth A. Reitzel, ${ }^{a}$ Joel Rosenblatt, ${ }^{a}$ Bahgat Z. Gerges, ${ }^{a}$ Nylev Vargas-Cruz, ${ }^{a}$ Issam I. Raada

aDepartment of Infectious Diseases, Infection Control, and Employee Health, University of Texas MD Anderson Cancer Center, Houston, Texas, USA

Volume 64, no. 4, e02146-19, 2020, https://doi.org/10.1128/AAC.02146-19. The following paragraph should be included at the end of the article text:

\section{ACKNOWLEDGMENTS}

I. I. Raad and J. Rosenblatt are inventors of the minocycline-EDTA-ethanol catheter lock solution technology which is owned by the University of Texas MD Anderson Cancer Center (UTMDACC) and has been licensed to Novel Anti-Infective Technologies, LLC, in which Drs. Raad and Rosenblatt and UTMDAAC are shareholders, and has been sublicensed to Citius Pharmaceuticals Inc., for whom Dr. Raad is a scientific advisor and shareholder and Dr. Rosenblatt is a consultant and shareholder. 